\title{
Mesomorphic lanthanide complexes with azomethine ligands
}

\author{
Rik Van Deun, Koen Binnemans* \\ K.U. Leuven, Department of Chemistry, Coordination Chemistry Division, Celestijnenlaan 200F, B-3001 Heverlee (Leuven), Belgium
}

\begin{abstract}
The synthesis and mesophase behaviour of lanthanide complexes with azomethine (Schiff base) ligands is described. The ligands are 4-tetradecyloxy- $N$-alkyl-2-hydroxybenzaldimines, where the alkyl chain on the imine nitrogen is $\mathrm{C}_{8} \mathrm{H}_{17}, \mathrm{C}_{12} \mathrm{H}_{25}$ or $\mathrm{C}_{18} \mathrm{H}_{37} \cdot \mathrm{The}$ stoichiometry of the complexes formed by the reaction of the hydrated nitrates of the lanthanides with the azomethines is $\left[\mathrm{Ln}(\mathrm{LH})_{3}\left(\mathrm{NO}_{3}\right)_{3}\right]$. All these coordination compounds exhibit liquid-crystalline properties. A viscous smectic A (SmA) mesophase is formed. The mesophase of these metallomesogens can be supercooled to a glassy state. (C) 2000 Elsevier Science S.A. All rights reserved.
\end{abstract}

Keywords: Lanthanides; Rare earths; Metallomesogens; Liquid crystals; Schiff base; Smectic mesophases

\section{Introduction}

When a rare-earth complex is heated, normally it either decomposes or melts to an isotropic liquid. However, it is possible to design rare-earth complexes which will pass, on heating, through a so-called mesophase before melting to the isotropic liquid. A compound in a mesophase can be considered to be a strongly disordered solid or an ordered liquid, and is termed a "liquid crystal". Metal-containing liquid crystals (metallomesogens) have attracted a lot of attention [1-7], but only a limited number of liquidcrystalline lanthanide complexes has been reported in the literature [8].The first mesomorphic lanthanide compounds were the substituted bis(phthalocyaninato)lutetium(III) complexes, described by Piechocki et al. [9]; these compounds exhibit columnar mesophases. Later, Galyametdinov and coworkers described calamitic lanthanide complexes with Schiff bases [10,11] and $\beta$-enaminoketones [12] as the ligands, showing a smectic A mesophase. Binnemans et al. showed that the transition temperatures of the Schiff base complexes are greatly influenced by the choice of the counter-ion [13], and they were able to show that the lanthanide contraction has a distinct influence on the transition temperatures of this type of compound [14].

In the paper, we describe the synthesis and thermal

\footnotetext{
*Corresponding author. Tel.: +32-16-32-7446; fax: +32-16-32-7992

E-mail address: koen.binnemans@chem.kuleuven.ac.be (K. Binnemans)
}

behaviour of other examples of mesomorphic rare-earth complexes with azomethine (Schiff base) ligands. The ligands are 4-tetradecyloxy- $N$-alkyl-2-hydroxybenzaldimines, where the alkyl chain on the imine nitrogen is $\mathrm{C}_{8} \mathrm{H}_{17}, \mathrm{C}_{12} \mathrm{H}_{25}$ or $\mathrm{C}_{18} \mathrm{H}_{37}$. The influence of this chain length on the transition temperatures is discussed.

\section{Experimental details}

\subsection{Techniques}

${ }^{1} \mathrm{H}-\mathrm{NMR}$ spectra were obtained on a Bruker DRX-400 spectrometer (400 MHz), a Bruker AMX-400 spectrometer (400 MHz), or a Bruker WM-250 spectrometer (250 MHz), using $\mathrm{CDCl}_{3}$ as solvent and tetramethylsilane (TMS) as internal standard. The $\delta$ values are expressed in ppm. IR spectra were recorded on a Bruker FTIR spectrometer IFS66. $\mathrm{KBr}$ pellets of the samples were used for the FTIR spectra. Elemental analyses (CHN) were performed on a CE Instruments EA-1110 elemental analyser. Differential scanning calorimetry (DSC) measurements were carried out on a Mettler-Toledo DSC821e module. Samples of $2-5 \mathrm{mg}$ in solid form were placed in aluminium pans (40 $\mu \mathrm{l})$ with a pierced lid, and heated or cooled at a scan rate of $10^{\circ} \mathrm{C} \mathrm{min}^{-1}$ under a nitrogen flow. Indium metal was used as standard for the calibration of the instrument $\left(T_{\mathrm{m}}=156.6 \pm 0.3^{\circ} \mathrm{C}, \Delta H_{\mathrm{m}}=28.45 \pm 0.6 \quad \mathrm{~J} \mathrm{~g} \mathrm{~g}^{-1}\right)$. Optical textures of the mesophases were observed with an 
Olympus BX60 polarising microscope equipped with a LINKAM TMS600 hot stage and a LINKAM TMS93 programmable temperature-controller. All chemicals were used as received, without further purification. Organic reagents were obtained from ACROS. Hydrated rare-earth nitrates were purchased from Aldrich.

\subsection{Synthesis of the compounds}

\subsubsection{4-Tetradecyloxy-2-hydroxybenzaldehyde (1)}<smiles>CCCCCCCCCCCCCCCCCC=O</smiles>

4-Tetradecyl-2-hydroxybenzaldehyde (1) was prepared by heating 2,4-dihydroxybenzaldehyde (20.73 g, $0.15 \mathrm{~mol}$ ) for $3 \mathrm{~h}$ at reflux with 1-bromotetradecane $(41.59 \mathrm{~g}, 0.15$ $\mathrm{mol})$ in $\mathrm{DMF}$, and with $\mathrm{KHCO}_{3}(15.04 \mathrm{~g}, 0.15 \mathrm{~mol})$ as the base. The crude aldehyde was purified by crystallisation from hot acetonitrile. Yield: 54\% (27 g). ${ }^{1} \mathrm{H}-\mathrm{NMR}(250$ $\left.\mathrm{MHz}, \mathrm{CDCl}_{3}, \delta \mathrm{ppm}\right): 0.90\left(\mathrm{t}, 3 \mathrm{H}, \mathrm{CH}_{3}\right), 1.0-1.6(\mathrm{~m}, 22 \mathrm{H}$, $\mathrm{CH}_{2}$ ), 1.80 (quintet, $2 \mathrm{H},-\mathrm{CH}_{2}-\mathrm{CH}_{2}-\mathrm{O}-$ ), $4.00(\mathrm{t}, 2 \mathrm{H}$, $\left.-\mathrm{CH}_{2}-\mathrm{O}-\right), 6.40\left(\mathrm{~d}, 1 \mathrm{H}, \mathrm{H}_{\mathrm{c}}\right), 6.50\left(\mathrm{dd}, 1 \mathrm{H}, \mathrm{H}_{\mathrm{b}}\right), 7.40(\mathrm{~d}$, $\left.1 \mathrm{H}, \mathrm{H}_{\mathrm{a}}\right), 9.70(\mathrm{~s}, 1 \mathrm{H}, \mathrm{CHO})$.

\subsubsection{4-Tetradecyloxy-N-octyl-2-hydroxybenzaldimine (2)}

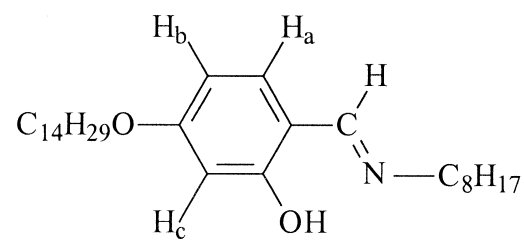

4-Tetradecyloxy-N-octyl-2-hydroxybenzaldimine (2) was prepared by heating $7.75 \mathrm{~g}(23 \mathrm{mmol})$ of aldehyde 1 with $2.95 \mathrm{~g}(23 \mathrm{mmol})$ of n-octylamine in absolute ethanol for $3 \mathrm{~h}$ at reflux, with a few drops of glacial acetic acid as the catalyst. The crude product was crystallised several times from hot absolute ethanol. Yield: $30 \%$ (3.07 g). ${ }^{1} \mathrm{H}-\mathrm{NMR}\left(400 \mathrm{MHz}, \mathrm{CDCl}_{3}, \delta \mathrm{ppm}\right): 0.88\left(\mathrm{t}, 6 \mathrm{H}, \mathrm{CH}_{3}\right.$ ), 1.24-1.46 (m, 32H, $\mathrm{CH}_{2}$ ), 1.67 (quintet, $2 \mathrm{H},-\mathrm{CH}_{2}-\mathrm{CH}_{2}-$ $\mathrm{N}-$ ), 1.77 (quintet, $2 \mathrm{H},-\mathrm{CH}_{2}-\mathrm{CH}_{2}-\mathrm{O}-$ ), $3.51(\mathrm{t}, 2 \mathrm{H}$, $\left.-\mathrm{CH}_{2}-\mathrm{N}-\right), 3.96\left(\mathrm{t}, 2 \mathrm{H},-\mathrm{CH}_{2}-\mathrm{O}-\right), 6.33\left(\mathrm{dd}, 1 \mathrm{H}, \mathrm{H}_{\mathrm{b}}\right)$, $6.37\left(\mathrm{~d}, 1 \mathrm{H}, \mathrm{H}_{\mathrm{c}}\right), 7.05\left(\mathrm{~d}, 1 \mathrm{H}, \mathrm{H}_{\mathrm{a}}\right), 8.09(\mathrm{~s}, 1 \mathrm{H}, \mathrm{CH}=\mathrm{N})$, $14.1(\mathrm{~s}, 1 \mathrm{H}, \mathrm{OH}), J_{\mathrm{o}}=8.5 \mathrm{~Hz}, J_{\mathrm{m}}=2.5 \mathrm{~Hz}$. Calc. for $\mathrm{C}_{29} \mathrm{H}_{51} \mathrm{NO}_{2}$ : C 78.14\%, H 11.53\%, N 3.14\%. Found: C $78.11 \%$, H $11.56 \%$, N $2.99 \%$.
2.2.3. 4-Tetradecyloxy-N-dodecyl-2-hydroxybenzaldimine (3)

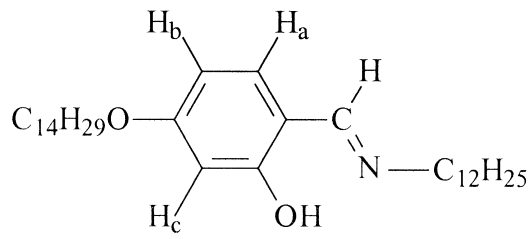

4-Tetradecyloxy- $N$-dodecyl-2-hydroxybenzaldimine (3) was prepared by heating for $3 \mathrm{~h}$ at reflux $4.12 \mathrm{~g}(12.3$ $\mathrm{mmol}$ ) of aldehyde 1 with $2.29 \mathrm{~g}(12.3 \mathrm{mmol})$ of $\mathrm{n}$ dodecylamine in absolute ethanol, with a few drops of glacial acetic acid as the catalyst. The crude product was crystallised several times from hot absolute ethanol. Yield: $88 \%$ (5.42 g). ${ }^{1} \mathrm{H}-\mathrm{NMR}$ (250 MHz, $\mathrm{CDCl}_{3}, \delta \mathrm{ppm}$ ): 0.88 $\left(\mathrm{t}, 6 \mathrm{H}, \mathrm{CH}_{3}\right), 1.03-1.56\left(\mathrm{~m}, 40 \mathrm{H}, \mathrm{CH}_{2}\right), 1.67$ (quintet, $2 \mathrm{H}$, $-\mathrm{CH}_{2}-\mathrm{CH}_{2}-\mathrm{N}-$ ), 1.77 (quintet, $2 \mathrm{H},-\mathrm{CH}_{2}-\mathrm{CH}_{2}-\mathrm{O}-$ ), 3.51 (t, 2H, $\left.-\mathrm{CH}_{2}-\mathrm{N}-\right), 3.95$ (t, 2H, $\left.-\mathrm{CH}_{2}-\mathrm{O}-\right), 6.33$ (dd, $\left.1 \mathrm{H}, \mathrm{H}_{\mathrm{b}}\right), 6.36\left(\mathrm{~d}, 1 \mathrm{H}, \mathrm{H}_{\mathrm{c}}\right), 7.04\left(\mathrm{~d}, 1 \mathrm{H}, \mathrm{H}_{\mathrm{a}}\right), 8.09(\mathrm{~s}, 1 \mathrm{H}$, $\mathrm{CH}=\mathrm{N}), 14.1(\mathrm{~s}, 1 \mathrm{H}, \mathrm{OH}), J_{\mathrm{o}}=8.5 \mathrm{~Hz}, J_{\mathrm{m}}=2.5 \mathrm{~Hz}$. Calc. for $\mathrm{C}_{33} \mathrm{H}_{59} \mathrm{NO}_{2}$ : C $78.98 \%, \mathrm{H} 11.85 \%$, N 2.79\%. Found: $\mathrm{C}$ $78.93 \%, \mathrm{H} 11.90 \%$, N $2.56 \%$.

\subsubsection{4-Tetradecyloxy-N-octadecyl-2-}

hydroxybenzaldimine (4)

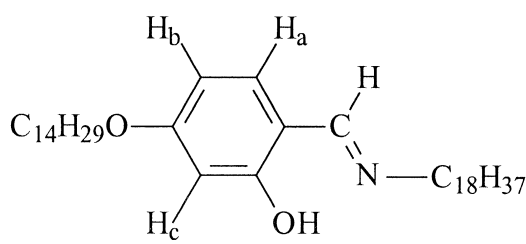

4 - Tetradecyloxy - $N$ - octadecyl - 2 - hydroxybenzaldimine (4) was prepared by heating for $3 \mathrm{~h}$ at reflux $16.73 \mathrm{~g} \mathrm{(50}$ mmol) of aldehyde 1 with $13.50 \mathrm{~g}$ (50 mmol) of $\mathrm{n}$ octadecylamine in n-heptane, with a few drops of glacial acetic acid as the catalyst. The crude product was crystallised several times from hot n-heptane. Yield: 40\% (11.6 g). ${ }^{1} \mathrm{H}-\mathrm{NMR}\left(400 \mathrm{MHz}, \mathrm{CDCl}_{3}, \delta \mathrm{ppm}\right): 0.88\left(\mathrm{t}, 6 \mathrm{H}, \mathrm{CH}_{3}\right)$, 1.10-1.50 (m, 52H, $\left.\mathrm{CH}_{2}\right), 1.67$ (quintet, $2 \mathrm{H},-\mathrm{CH}_{2}-\mathrm{CH}_{2}-$ $\mathrm{N}-$ ), 1.77 (quintet, $2 \mathrm{H},-\mathrm{CH}_{2}-\mathrm{CH}_{2}-\mathrm{O}-$ ), 3.50 (t, $2 \mathrm{H}$, $\left.-\mathrm{CH}_{2}-\mathrm{N}-\right), 3.95\left(\mathrm{t}, 2 \mathrm{H},-\mathrm{CH}_{2}-\mathrm{O}-\right), 6.32\left(\mathrm{dd}, 1 \mathrm{H}, \mathrm{H}_{\mathrm{b}}\right)$, $6.36\left(\mathrm{~d}, 1 \mathrm{H}, \mathrm{H}_{\mathrm{c}}\right), 7.05\left(\mathrm{~d}, 1 \mathrm{H}, \mathrm{H}_{\mathrm{a}}\right), 8.08(\mathrm{~s}, 1 \mathrm{H}, \mathrm{CH}=\mathrm{N}), 14.1$ $(\mathrm{s}, 1 \mathrm{H}, \mathrm{OH}), J_{\mathrm{o}}=8.5 \mathrm{~Hz}, J_{\mathrm{m}}=2.5 \mathrm{~Hz}$. Calc. for $\mathrm{C}_{39} \mathrm{H}_{71} \mathrm{NO}_{2}$ : C 79.94\%, H 12.21\%, N 2.39\%. Found: C $80.23 \%, \mathrm{H} 12.16 \%$, N $2.30 \%$.

\subsubsection{La complex (11)}

Compound 11 was prepared by adding a solution of 0.37 $\mathrm{g}(0.85 \mathrm{mmol})$ of $\mathrm{La}\left(\mathrm{NO}_{3}\right)_{3} \cdot 6 \mathrm{H}_{2} \mathrm{O}$ in absolute ethanol dropwise to a stirred solution of $0.50 \mathrm{~g}(0.85 \mathrm{mmol})$ of the ligand $\mathrm{LH}$ in absolute ethanol, at a temperature not higher than $50^{\circ} \mathrm{C}$. After ca. $15 \mathrm{~min}$, the solution turned cloudy, 
indicating that the product started to precipitate. Stirring was continued for at least $3 \mathrm{~h}$. The pale yellow precipitate was filtered on a crucible, washed with ice-cold absolute ethanol and dried in vacuo. Yield: $76 \%(0.45 \mathrm{~g}) .{ }^{1} \mathrm{H}-\mathrm{NMR}$ (250 MHz, $\left.\mathrm{CDCl}_{3}, \delta \mathrm{ppm}\right): 0.88\left(\mathrm{~m}, 6 \mathrm{H}, \mathrm{CH}_{3}\right), 1.10-1.40$ $\left(\mathrm{m}, 52 \mathrm{H}, \mathrm{CH}_{2}\right), 1.62\left(\mathrm{~m}, 4 \mathrm{H}, \mathrm{N}-\mathrm{CH}_{2}-\mathrm{CH}_{2}\right.$ and $\mathrm{CH}_{2}-$ $\left.\mathrm{CH}_{2}-\mathrm{O}\right), 3.46$ (t, 2H, N-CH $), 3.64$ (t, 2H, $\left.\mathrm{CH}_{2}-\mathrm{O}\right), 6.15$ $\left(\mathrm{dd}, 1 \mathrm{H}, \mathrm{H}_{\mathrm{b}}\right), 6.33\left(\mathrm{~d}, 1 \mathrm{H}, \mathrm{H}_{\mathrm{c}}\right), 6.90\left(\mathrm{~d}, 1 \mathrm{H}, \mathrm{H}_{\mathrm{a}}\right), 7.60(\mathrm{~d} 1 \mathrm{H}$, $\mathrm{CH}=\mathrm{N}), 12.2(\mathrm{~s}, 1 \mathrm{H}, \mathrm{OH}), J_{\mathrm{o}}=8.5 \mathrm{~Hz}, J_{\mathrm{m}}=2.5 \mathrm{~Hz}$. IR $\left(\mathrm{KBr}\right.$ pellet, $\left.\mathrm{cm}^{-1}\right): 3200(\mathrm{~m}, \nu(\mathrm{OH})), 2920,2860(\mathrm{~s}$, aliphatic $\mathrm{C}-\mathrm{H}$ stretch), $1620(\mathrm{~s}, \nu(\mathrm{C}=\mathrm{N})), 1530(\mathrm{~s}, \nu(\mathrm{C}=\mathrm{C}))$, $1290\left(\mathrm{~s}, \nu\left(\mathrm{C}_{\mathrm{Ph}}-\mathrm{O}\right)\right), 1230\left(\mathrm{~s}, \nu_{\mathrm{as}}(\mathrm{C}-\mathrm{O}-\mathrm{C})\right), 1030\left(\mathrm{~s}, \nu_{\mathrm{s}}(\mathrm{C}-\right.$ $\mathrm{O}-\mathrm{C})), 590(\mathrm{~m}, \nu(\mathrm{La}-\mathrm{O}))$. The elemental analysis results are given in Table 1. All the other rare-earth complexes were synthesised in an analogous way.

\section{Results and discussion}

Ligands 2-4 were synthesised in a two-step reaction, in which the hydroxy group in the 4-position in 2,4-dihydroxybenzaldehyde is first replaced by an alkoxy chain, followed by formation of the Schiff base by reaction of the aldehyde with an alkyl amine (Scheme 1). 4-Tetradecyloxy-2-hydroxybenzaldehyde (1) was prepared by refluxing (for $3 \mathrm{~h}$ ) 2,4-dihydroxybenzaldehyde (1 eq.) with 1-bromotetradecane (1 eq.) in DMF, with $\mathrm{KHCO}_{3}$ (1 eq.) as the base. The crude aldehyde was crystallised from acetonitrile and transformed to the Schiff base by refluxing in absolute ethanol ( $3 \mathrm{~h}$ ) with the respective alkyl amine (1 eq.), using a few drops of glacial acetic acid as the catalyst. The Schiff bases 4-tetradecyloxy- $N$-alkyl-2-hydroxybenzaldimines were purified by crystallising several times from absolute ethanol. The overall yield varied between 30 and $88 \%$. The ligands were characterised by NMR, IR spectroscopy and by $\mathrm{CHN}$ analysis. The rare-earth complexes 5-14 were prepared by dissolving the Schiff base in absolute ethanol and adding a solution of the hydrated rare-earth nitrate in absolute ethanol. Although a complex is formed in a 1:3 metal/ligand ratio, we used an excess of the hydrated rare-earth nitrate, in order to take the uncertainty of the water content of these reagents into account. The dissolution of the Schiff base can be assisted by heating the ethanolic solution, but reproducible results for the complexes could only be obtained if the solution was cooled below $50^{\circ} \mathrm{C}$ before the solution of the rare-earth salt was added dropwise. About $15 \mathrm{~min}$ after mixing, the solution turned cloudy and the complex started to precipitate. Stirring was continued for at least $3 \mathrm{~h}$. After filtration, the complex was washed with ice-cold ethanol and dried in vacuo. The yield of the complexes varied between 56 and $96 \%$. The complexes were characterised by $\mathrm{CHN}$ elemental analysis (Table 1). All the complexes have the stoichiometry $\left[\mathrm{Ln}(\mathrm{LH})_{3}\left(\mathrm{NO}_{3}\right)_{3}\right][14,15]$. In the complexes, the Schiff base is present in a zwitterionic form. The phenolic hydrogen is transferred to the imine nitrogen and coordination occurs through the phenolic oxygen only. The imine nitrogen is not coordinated. For each lanthanide ion, three nitrate groups are present as counter-ions.

The azomethine ligands do not show liquid-crystalline properties, but melt directly to an isotropic liquid. However, all the rare-earth complexes exhibit a mesophase (Table 2). The compounds are enantiotropic liquid crystals, except for the Ho complex (7), which is a monotropic liquid crystal. A typical DSC trace is shown in Fig. 1. The mesophase was identified as a smectic A (SmA) phase by optical microscopy, using a hot stage and polarised light. The sample was placed between two untreated cover glasses. By cooling from the isotropic melt, bâtonnets formed, which coalesced to form a focal-conic fan structure. In the same sample, extinct regions were also observed, indicating homeotropic alignment of the molecules. This supports the identification as the smectic A phase. In a smectic A mesophase, the complexes form layers, and the long molecular axis of the complexes is, on average, perpendicular to the layer planes [16]. When cooling the mesophase, no crystallisation was observed under the microscope and the texture of the mesophase

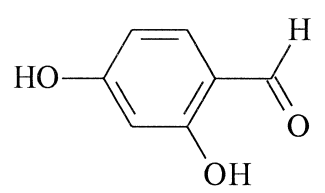

(a)
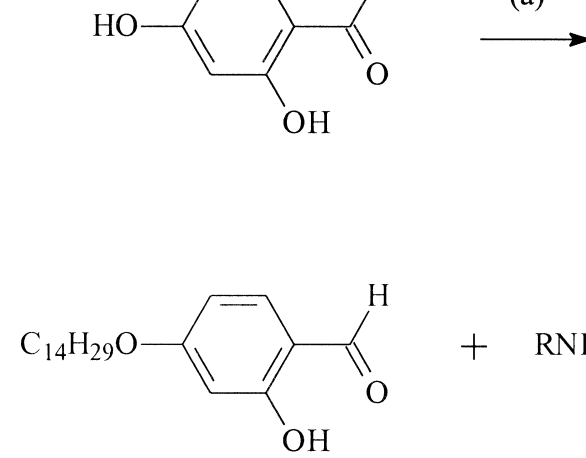

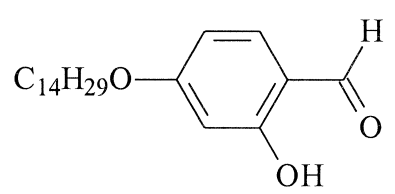

(1)

Scheme 1. Synthesis of the azomethine ligands 2-4. Experimental conditions: (a) $\mathrm{C}_{14} \mathrm{H}_{29} \mathrm{Br} \mathrm{KHCO}_{3}$, DMF (reflux, 3 h); (b) ethanol or n-heptane (reflux, 3 h), glacial acetic acid (catalyst). 
Table 1

Overview and analysis results for the mesomorphic rare-earth complexes $\left[\mathrm{Ln}(\mathrm{LH})_{3}\left(\mathrm{NO}_{3}\right)_{3}\right]$ with azomethine ligands

\begin{tabular}{|c|c|c|c|c|c|c|}
\hline Compound & Ln & $\mathrm{LH}^{\mathrm{a}}$ & $\% \mathrm{C}^{\mathrm{b}}$ & $\% \mathrm{H}^{\mathrm{b}}$ & $\% \mathrm{~N}^{\mathrm{b}}$ & Yield (\%) \\
\hline 5 & $\mathrm{Nd}$ & 2 & $62.31(62.27)$ & $9.21(9.25)$ & $4.90(5.04)$ & 57 \\
\hline 6 & $\mathrm{Gd}$ & 2 & $62.20(62.18)$ & $9.20(9.18)$ & $4.86(5.00)$ & 56 \\
\hline 7 & Ho & 2 & $61.85(61.90)$ & $9.14(9.14)$ & $4.82(4.98)$ & 62 \\
\hline 8 & $\mathrm{Nd}$ & 3 & $64.08(64.77)$ & $9.65(9.72)$ & $4.44(4.58)$ & 71 \\
\hline 9 & $\mathrm{Gd}$ & 3 & $63.52(64.32)$ & $9.49(9.65)$ & $4.43(4.54)$ & 74 \\
\hline 10 & Ho & 3 & $63.80(64.05)$ & $9.52(9.61)$ & $4.43(4.53)$ & 63 \\
\hline 11 & $\mathrm{La}$ & 4 & $68.38(67.47)$ & $10.46(10.31)$ & $3.63(4.03)$ & 76 \\
\hline 12 & $\mathrm{Nd}$ & 4 & $66.84(67.29)$ & $10.16(10.28)$ & $3.98(4.02)$ & 96 \\
\hline 13 & $\mathrm{Gd}$ & 4 & $66.73(66.88)$ & $10.21(10.22)$ & $3.78(4.00)$ & 91 \\
\hline 14 & Но & 4 & $66.59(66.64)$ & $10.19(10.18)$ & $3.75(3.98)$ & 92 \\
\hline
\end{tabular}

${ }^{\text {a }}$ Ligands: 2, 4-tetradecyloxy- $N$-octyl-2-hydroxybenzaldimine; 3, 4-tetradecyloxy- $N$-dodecyl-2-hydroxybenzaldimine; 4, 4-tetradecyloxy- $N$-octadecyl-2hydroxybenzaldimine.

${ }^{\mathrm{b}}$ Calculated values are given in parentheses.

was frozen into the solid state. A glassy mesophase was formed. Glass formation was noticed from the fact that it was no longer possible to shear the cover glasses between which the sample was sandwiched. Moreover, when cooling further, conchoidal fractures were observed in the texture. These conchoidal fractures also indicate the presence of a glassy state. The DSC traces showed crystallisation at a cooling rate of $10^{\circ} \mathrm{C} \mathrm{min}{ }^{-1}$, although a strong supercooling was observed. These differences in behaviour between the microscopic and DSC observations do not contradict each other, because we were studying a

Table 2

Thermal behaviour of the azomethine ligands and the rare-earth complexes

\begin{tabular}{|c|c|c|c|}
\hline Compound & Transition $^{\mathrm{a}}$ & $\begin{array}{l}\text { Temperature } \\
\left({ }^{\circ} \mathrm{C}\right)\end{array}$ & $\begin{array}{l}\Delta H \\
\left(\mathrm{~kJ} \mathrm{~mol}^{-1}\right)\end{array}$ \\
\hline 2 & Crys $\rightarrow$ I & 37 & 74.5 \\
\hline 3 & Crys $\rightarrow$ I & 50 & 87.6 \\
\hline 4 & Crys $\rightarrow \mathrm{I}$ & 73 & 86.0 \\
\hline \multirow[t]{2}{*}{5} & Crys $\rightarrow$ SmA & 116 & 15.6 \\
\hline & $\mathrm{SmA} \rightarrow \mathrm{I}$ & 158 & 10.9 \\
\hline \multirow[t]{2}{*}{6} & Crys $\rightarrow$ SmA & 125 & 21.4 \\
\hline & $\mathrm{SmA} \rightarrow \mathrm{I}$ & 143 & 10.2 \\
\hline \multirow[t]{2}{*}{$7^{\mathrm{b}}$} & Crys $\rightarrow \mathrm{I}$ & 143 & 42.7 \\
\hline & $\mathrm{I} \rightarrow \mathrm{SmA}$ & 133 & 9.6 \\
\hline \multirow[t]{2}{*}{8} & Crys $\rightarrow$ SmA & 106 & 19.0 \\
\hline & $\mathrm{SmA} \rightarrow \mathrm{I}$ & 160 & 12.2 \\
\hline \multirow[t]{2}{*}{9} & Crys $\rightarrow$ SmA & 130 & 23.0 \\
\hline & $\mathrm{SmA} \rightarrow \mathrm{I}$ & 150 & 12.5 \\
\hline \multirow[t]{2}{*}{10} & Crys $\rightarrow$ SmA & 138 & 33.3 \\
\hline & $\mathrm{SmA} \rightarrow \mathrm{I}$ & 144 & 9.9 \\
\hline \multirow[t]{2}{*}{11} & Crys $\rightarrow$ SmA & 92 & 5.2 \\
\hline & $\mathrm{SmA} \rightarrow \mathrm{I}$ & 138 & 10.8 \\
\hline \multirow[t]{2}{*}{12} & Crys $\rightarrow$ SmA & 102 & 14.7 \\
\hline & $\mathrm{SmA} \rightarrow \mathrm{I}$ & 155 & 10.6 \\
\hline \multirow[t]{2}{*}{13} & Crys $\rightarrow$ SmA & 115 & 25.6 \\
\hline & $\mathrm{SmA} \rightarrow \mathrm{I}$ & 145 & 10.6 \\
\hline \multirow[t]{2}{*}{14} & Crys $\rightarrow$ SmA & 132 & 30.9 \\
\hline & $\mathrm{SmA} \rightarrow \mathrm{I}$ & 141 & 11.9 \\
\hline
\end{tabular}

\footnotetext{
${ }^{a}$ Crys, crystalline phase; SmA, smectic A phase; I, isotropic phase.

${ }^{\mathrm{b}}$ Compound 7 shows a SmA mesophase on cooling from the isotropic liquid only (monotropic liquid crystal).
}

thin film under the microscope, whereas a bulk sample was used for the DSC measurements.

When going from the neodymium(III) complex, to the gadolinium(III) complex, to the holmium(III) complex, the mesophase stability range decreases. In fact, the melting point gradually increases over the lanthanide series, and at the same time the clearing point decreases. This is in agreement with the findings of Binnemans et al. [14] for other nitrate complexes. The length of the alkyl chain has considerably less influence on the transition temperature than the central metal ion.

\section{Conclusions}

In this paper, the mesomorphic properties of some lanthanide complexes with azomethine ligands are discussed. It is shown that the lanthanide ion can induce mesomorphism in non-mesomorphic azomethine ligands, by forming complexes with stoichiometry $\left[\mathrm{Ln}(\mathrm{LH})_{3}\left(\mathrm{NO}_{3}\right)_{3}\right]$, where $\mathrm{Ln}$ is a lanthanide ion, $\mathrm{LH}$ is the ligand and $\mathrm{NO}_{3}$ is the counter ion. These complexes all show smectic A mesophases on cooling from the isotropic melt. The mesophase can be supercooled to a glassy state.

\section{Acknowledgements}

$\mathrm{KB}$ is a Postdoctoral Fellow of the F.W.O., Flanders (Belgium). He thanks the F.W.O. for a "Krediet aan Navorsers" and Prof. C. Görller-Walrand for laboratory facilities. RVD (specialisatiebursaal IWT) is indebted to the "Flemish Institute for the Encouragement of Scientific and Technological Research in Industry (IWT)" for financial support. The authors wish to thank Prof. Duncan W. Bruce (University of Exeter, UK), and Prof. Yury G. Galyametdinov (Russian Academy of Sciences, Kazan, Russia) for useful discussions. The CHN microanalyses were performed by Ms. P. Bloemen. 


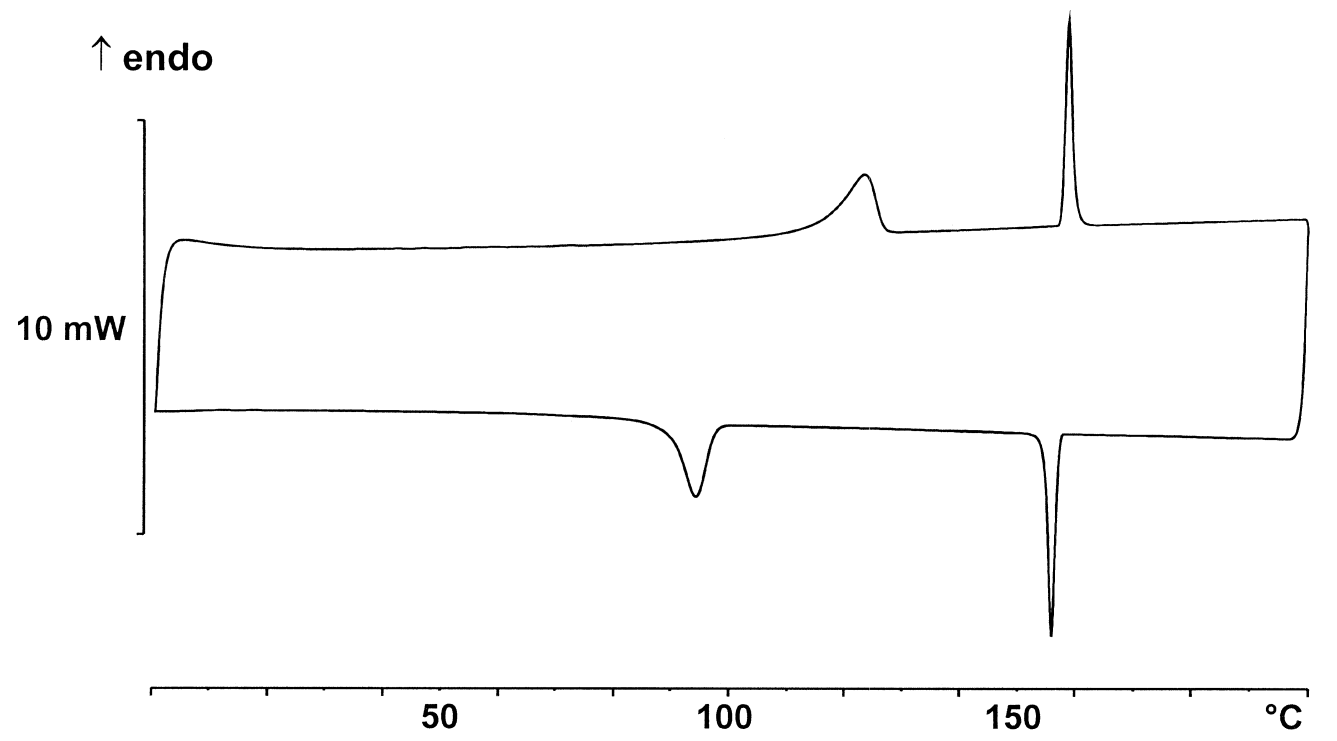

Fig. 1. DSC trace of compound 5. Endothermic peaks point upwards. The upper trace shows the second heating run, the lower trace shows the second cooling run.

\section{References}

[1] A.M. Giroud-Godquin, P.M. Maitlis, Angew. Chem. Int. Ed. Engl. 30 (1991) 375.

[2] P. Espinet, M.A. Esteruelas, L.A. Oro, J.L. Serrano, E. Sola, Coord. Chem. Rev. 117 (1992) 215.

[3] S.A. Hudson, P.M. Maitlis, Chem. Rev. 93 (1993) 861

[4] D.W. Bruce, J. Chem. Soc., Dalton Trans. (1993) 2983.

[5] A.P. Polishchuk, T.V. Timofeeva, Russ. Chem. Rev. 62 (1993) 291.

[6] J.L. Serrano (Ed.), Metallomesogens, VCH, Weinheim, 1996.

[7] D.W. Bruce, in: D.W. Bruce, D. O'Hare (Eds.), Inorganic Materials, 2nd Edition, Wiley, Chichester, 1996, p. 429, Chapter 8.

[8] K. Binnemans, Mater. Sci. Forum 315-317 (1999) 169.

[9] C. Piechocki, J. Simon, J.J. André, D. Guillon, P. Petit, A. Skoulios, P. Weber, Chem. Phys. Lett. 122 (1985) 124.

[10] Yu.G. Galyametdinov, G.I. Ivanova, I.V. Ovchinnikov, Bull. Acad. Sci. USSR, Div. Chem. Sci. 40 (1991) 1109.
[11] Yu.G. Galyametdinov, M.A. Athanassopoulou, K. Griesar, O.A. Kharitonova, E.A. Soto-Bustamante, L. Tinchurina, I.V. Ovchinnikov, W. Haase, Chem. Mater. 8 (1996) 922.

[12] Yu.G. Galyametdinov, O.A. Kharitonova, O.N. Kadkin, I.V. Ovchinnikov, Russ. Chem. Bull. 43 (1994) 1595.

[13] K. Binnemans, Yu.G. Galyametdinov, S.R. Collinson, D.W. Bruce, J. Mater. Chem. 8 (1998) 1551.

[14] K. Binnemans, R. Van Deun, D.W. Bruce, Yu.G. Galyametdinov, Chem. Phys. Lett. 300 (1999) 509.

[15] K. Binnemans, D.W. Bruce, S.R. Collinson, R. Van Deun, Yu.G. Galyametdinov, F. Martin, Phil. Trans. R. Soc. Lond. A 357 (1999) 3063.

[16] P.J. Collings, H. Hird, Introduction to Liquid Crystals, Taylor and Francis, London, 1997. 